\title{
Solubility of Lead Chloride in Hydrochloric Acid Solutions of Low to High Concentrations: A Pitzer Approach
}

\author{
JAY JE-Hun JANG*, LESLIE KIRKES, \\ AND LUZHENG ZHANG
}

Sandia National Laboratories ${ }^{1}, 4100$ National Parks Highway, Building A, Carlsbad, New Mexico, 88220, U.S.A.

(*Corresponding author, email: jjang@sandia.gov)

Waste Isolation Pilot Plant, WIPP, is the only actively operational deep geological repository in the world to permanently isolate defense-related transuranic (TRU) nuclear waste. WIPP is located $\sim 26$ miles southeast of Carlsbad, New Mexico, U.S.A., built 2,150 feet underground in the Salado Formation, a thick Permian evaporite deposit in the northern Delaware Basin. Due to the use of shielded containers for handling and placing the remote-handled waste, the inventory of lead in the waste (both contact- and remote-handled) is significantly larger than the actinides in the waste. After the closure of the repository, the lingering oxygen will be depleted by oxygen-driven metal corrosion and biological activities. The anoxic corrosion of the lead used in the waste and containers in the presence of the infiltrating chloride-rich brine would be the primary source of dissolved lead over the performance period of the repository.

The extensive complexation of the dissolved lead, $\mathrm{Pb}^{+2}$, with chloride, $\mathrm{Cl}^{-}$, is important in understanding the overall aqueous chemistry of lead. From the literature, we collected the experimental solubility data of lead chloride $\left(\mathrm{PbCl}_{2}\right)$ in solutions of hydrochloric acid $(\mathrm{HCl})$. The collected experimental data were compared to the models selected also from the literature.

Preliminary calculations using published Pitzer thermodynamic models revealed the need for improvement of the models, such as model redundancy and ambiguity in the selected data from the literature. The gaps noticed during the calculations and model validation will be discussed.

\footnotetext{
${ }^{1}$ Sandia National Laboratories is a multi-mission laboratory managed and operated by National Technology and Engineering Solutions of Sandia, LLC., a wholly owned subsidiary of Honeywell International, Inc., for the U.S. Department of Energy's National Nuclear Security Administration under contract DE-NA-0003525. This research is funded by WIPP programs administered by the Office of Environmental Management (EM) of the U.S Department of Energy. SAND2020-0870A
} 